\title{
Photogrammetric 3D Measurements Based on Immersive Panoramas
}

\begin{abstract}
This article presents the concept of photogrammetric measurements based on immersive video; i.e., video recorded by a mobile immersive camera. The camera records a series of $360^{\circ}$ images, which is facilitated by the application of a few cameras whose perspective centers are at some distance from the common "virtual" perspective center.

The aim of this article is to test the potential of panorama-based measurements and to analyze their accuracy. The article presents the immersive model geometry and the application of immersive imaging in a spherical model that is used in SfM software (e.g., Photoscan). The impact of immersive imaging parameters on the photogrammetric measurement accuracy was examined. The accuracy of panorama-based photogrammetric measurements depends on set sphere radius $R$ and its relationship with the distance to the points of object $D$ and location of the points on the individual images (expressed by angles $\varepsilon$ and $\xi$ ). The article analyzes how the modification of sphere radius $R$ and the radius of the masking circle influences the accuracy of the measurements based on immersive panoramas.

The outcomes of this research indicate that the sphere radius $R$ of the immersive panorama used in the photogrammetric measurements should be smaller than the average spatial reach of the survey points and the reduction of the masking circle lowers the number of mean errors on the ground control points. Immersive panoramas enable adjusting the sphere radius $(R)$ depending on the distance to the object. However, it is difficult to find the right sphere radius for the entire recorded the scene.
\end{abstract}

Keywords: panorama, immersive video, $360^{\circ}$ video, Ladybug camera, spherical photogrammetry

Received: 18 April 2017; accepted: 27 January 2018

\footnotetext{
* ArcelorMittal Poland, Automation, Industrial IT and Models, Kraków, Poland

** AGH University of Science and Technology, Faculty of Mining Surveying and Environmental Engineering, Chair for Geoinformation, Photogrammetry and Remote Sensing, Krakow, Poland

*** Work was done as part of the statutory research of AGH University No. 11.11.150.949.
} 


\section{Introduction and Motivation}

The aim of the research presented in this article is to investigate the photogrammetric potential of immersive video. The term "immersive video" refers here to $360^{\circ}$ omnidirectional imaging recorded with multiple sensors that leads to a "flawed" spherical or cylindrical panorama due to the offset of the projection centers of individual images [1]. Such images have gained popularity thanks to the Google Street View application, which uses panoramas recorded with immersive cameras.

In geodetic measurements, panoramas and video panoramas recorded with $360^{\circ}$ systems are mainly used as a visual background for laser scanning data (e.g., Leica Pegasus: Two, Topcon IP-S3, Satlab SLS-1). These systems are very expensive, but they provide accurate measurement data. Resignation from a laser scanner and relying on an immersive sensor significantly reduces the cost of the mobile system. At the same time, the measurement accuracy of such a system decreases. This is caused by the use of immersive images in a spherical or cylindrical model, which are assumed to have a common projection center for each panoramic image. As panoramic images are rarely employed in photogrammetry, only a few computer programs are suited to process them (e.g., Photoscan, Pix4D). What is more, they rely on panoramas that are assumed to be error-free. Therefore, processing immersive panoramas with such programs requires users to know the impact of the difference between the geometry of the immersive and spherical model on the accuracy of the determined coordinates.

In order to achieve the main goal of the research, it was necessary to complete a number of research tasks:

- analyze spherical and immersive panorama geometry, which included the designation of factors that affect panorama generation;

- determine the photogrammetric measurement errors on the basis of the immersive images in a spherical model;

- evaluate the impact of selected factors on increasing the accuracy of photogrammetric measurements based on the immersive video;

- perform test measurements to confirm the theoretical assumptions.

\section{Geometry of Immersive Panorama and Its Errors in Spherical Model}

Theoretical foundations related to immersive images start in various discussions about the errors in panoramic images [2-8] and are continued in [9-13]. There are two approaches to the generation of immersive panoramas: the first approach ignores the eccentricity of the projection centers of individual pinhole cameras. Such images are rarely used in photogrammetric projects; when they are used, their main purpose is to visualize sites. The second approach (Fig. 1a), represented by the manufacturers 
of Ladybug cameras [14], assumes that this error should be minimized by the application of a special algorithm for the image processing. The algorithm requires the setting of a radius value for the sphere $(R)$ (or cylinder) being created, and it should be as close as the distance to the object being captured $(D \approx R)$. What is more, the object points located on the sphere are not affected by the eccentricity. The points of the object located in the distance equal to the sphere radius (from the agreed "virtu$\mathrm{al}^{\prime \prime}$ perspective center) are recorded using a spherical model (Fig. 1b), and the other points are displaced - these displacements are called parallaxes (Fig. 1c).

Among immersive sensors, the Ladybug camera by Flir Integrated Imaging (previously Point Grey Research) is widely used. The Ladybug® 3 model was used in this research project. It consists of six identical wide-angle cameras, with five of them having axes placed in the horizontal plane. The sixth camera points upwards and is not considered in this research project. The sphere radius $(R)$ can be set in software dedicated to the Ladybug camera (e.g., LadybugCapPro).

The algorithm of the panorama creation for this camera consists of three stages [15]:

1. Rectification of each raw image registered by a single pinhole camera for the influence of lens distortion.

2. Transformation of the imaging coordinates of the rectified image to the $3 \mathrm{D}$ coordinate system of the individual camera.

3. Transformation of the coordinates in the 3D coordinate system of the individual camera into the coordinate system of the whole camera; the sphere radius $(R)$ is then set.

a)

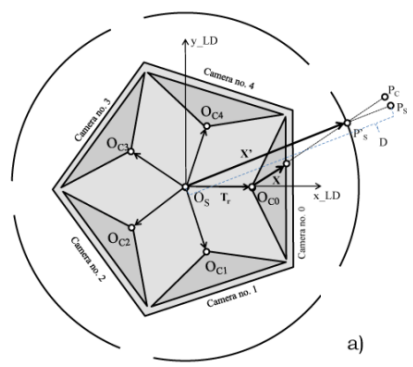

b)

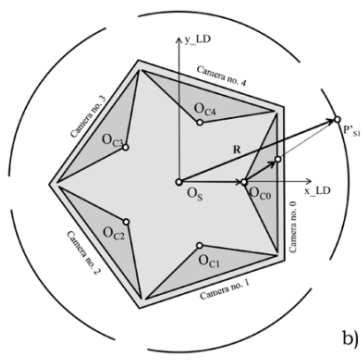

c)

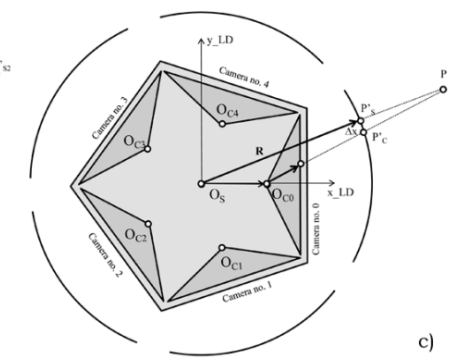

Fig. 1. Immersive model: a) geometry of the model (view from top); b) sphere radius $(R)$ compatible with distance to point $\mathrm{P}_{{ }^{\prime}}$; ) parallax error $(\Delta x)$ on immersive panorama caused by using spherical model; radius $(R)$ is not the same as distance to point $\mathrm{P}_{S 2}^{\prime}$. Explanations: $D$ - distance from coordinate system of immersive camera to object; $\mathrm{O}_{\mathrm{s}}$ - origin of coordinate system of immersive camera with axes $x_{-} L D, y_{-} L D$, and z_LD; "virtual" perspective center of immersive camera; $\mathrm{O}_{c}$ - perspective center of individual camera; $\mathrm{X}$ - imaging vector in single pinhole camera coordinate system; $\mathbf{X}^{\prime}$ - imaging vector in immersive camera coordinate system; $\mathbf{T}_{r}-$ translation vector of origin of immersive camera $\left(\mathrm{O}_{\mathrm{s}}\right)$ to perspective center of single pinhole camera $\left(\mathrm{O}_{\mathrm{c}}\right)$; $R$-sphere radius of immersive panorama; $\Delta x$ - parallax error (elongated) 
The use of immersive imaging in the spherical model causes a number of errors that influence the accuracy of the photogrammetric measurements. The most important error is the parallax error, which is the difference between the location of image point $\mathrm{P}^{\prime}{ }_{c}$ created by a single pinhole camera with a perspective center $\mathrm{O}_{c}$ and a location of image point $\mathrm{P}_{\mathrm{s}}^{\prime}$ on the sphere with a center in $\mathrm{O}_{s}$.

Parallax errors are presented as [10]:

$$
\begin{aligned}
& \Delta x=\frac{(D-R) \cdot t \cdot \sin \varepsilon}{D} \\
& \Delta y=\frac{(D-R) \cdot t \cdot \sin \xi}{D}
\end{aligned}
$$

where:

$\varepsilon, \xi$ - horizontal and zenithal angles between the axis of a single pinhole camera and the direction of observation with an apex in $\mathrm{O}_{s^{\prime}}$

$t$ - displacement distance between $\mathrm{O}_{c}$ and $\mathrm{O}_{s^{\prime}}$

$D$ - distance from the perspective center of the immersive camera to the object.

As seen from Equations (1) and (2) above, the errors are at a maximum for the edges of the field of view of the single pinhole cameras $(\varepsilon, \xi=\max )$. The influence of the parallax errors is greater for points located inside the sphere than it is for those outside the sphere. Angles $\varepsilon, \xi$ can be limited by using a masking circle on the panorama in order to decrease the field of view of a single pinhole camera. For great distances $(D)$, the errors are negligible in the same way as the influence of eccentricity of a theodolite on the angle measurements for very long lines of sight. The sign of a parallax error is dependent on the location of a point in relation to the sphere (outside, inside) and also in relation to the axes of the single pinhole cameras. For this reason, it is important to properly situate two immersive panoramas; more precisely, to situate the position of the axes of the single pinhole cameras in the photogrammetric spatial intersection.

Table 1 presents examples of parallax errors $(\Delta x)$ for the Ladybug ${ }^{\circledR} 3$ camera for different sphere radii $(R)$, distances to objects $(D)$, and angles $(\varepsilon)$. The ground sampling distance (GSD) depends on the distance; the parallax errors are also presented in pixels in Table 1.

It is clear that, for a $D$ larger than $R$, the influence of parallax error is smaller than with GSD; however, for points inside the sphere, the influence is significant. The error can be reduced by limiting the fields of view of the single pinhole cameras. 
Table 1. Parallax errors $(\Delta x)$ in relation to angle $\varepsilon$ and distance $(D)$ for $R=10 \mathrm{~m}$ and $R=20 \mathrm{~m}$

\begin{tabular}{|c|c|c|c|c|c|c|}
\hline & $D$ & $1 \mathrm{~m}$ & $10 \mathrm{~m}$ & $20 \mathrm{~m}$ & $30 \mathrm{~m}$ & $40 \mathrm{~m}$ \\
\hline & $P_{\text {ter }}$ & $0.0013(3) \mathrm{m}$ & $0.013(3) \mathrm{m}$ & $0.026(6) \mathrm{m}$ & $0.039(9) \mathrm{m}$ & $0.053(3) \mathrm{m}$ \\
\hline \multicolumn{7}{|c|}{$\varepsilon=1^{\circ}$} \\
\hline \multirow{2}{*}{$\Delta x$} & $R=10 \mathrm{~m}$ & $\begin{array}{l}-0.006 \mathrm{~m} \\
(-4.5 \mathrm{pxl})\end{array}$ & $\begin{array}{l}0.000 \mathrm{~m} \\
(0.0 \mathrm{pxl})\end{array}$ & $\begin{array}{l}0.000 \mathrm{~m} \\
(0.0 \mathrm{pxl})\end{array}$ & $\begin{array}{l}0.000 \mathrm{~m} \\
(0.0 \mathrm{pxl})\end{array}$ & $\begin{array}{l}0.000 \mathrm{~m} \\
(0.0 \mathrm{pxl})\end{array}$ \\
\hline & $R=20 \mathrm{~m}$ & $\begin{array}{l}-0.013 \mathrm{~m} \\
(-10 \mathrm{pxl})\end{array}$ & $\begin{array}{c}-0.001 \mathrm{~m} \\
(0.0 \mathrm{pxl})\end{array}$ & $\begin{array}{l}0.000 \mathrm{~m} \\
(0.0 \mathrm{pxl})\end{array}$ & $\begin{array}{l}0.000 \mathrm{~m} \\
(0.0 \mathrm{pxl})\end{array}$ & $\begin{array}{l}0.000 \mathrm{~m} \\
(0.0 \mathrm{pxl})\end{array}$ \\
\hline \multicolumn{7}{|c|}{$\varepsilon=5^{\circ}$} \\
\hline \multirow{2}{*}{$\Delta x$} & $R=10 \mathrm{~m}$ & $\begin{array}{c}-0.031 \mathrm{~m} \\
(-23.5 \mathrm{pxl})\end{array}$ & $\begin{array}{l}0.000 \mathrm{~m} \\
(0.0 \mathrm{pxl})\end{array}$ & $\begin{array}{l}0.002 \mathrm{~m} \\
(0.0 \mathrm{pxl})\end{array}$ & $\begin{array}{l}0.002 \mathrm{~m} \\
(0.0 \mathrm{pxl})\end{array}$ & $\begin{array}{l}0.000 \mathrm{~m} \\
(0.0 \mathrm{pxl})\end{array}$ \\
\hline & $R=20 \mathrm{~m}$ & $\begin{array}{l}-0.066 \mathrm{~m} \\
(-50 \mathrm{pxl})\end{array}$ & $\begin{array}{c}-0.003 \mathrm{~m} \\
(0.0 \mathrm{pxl})\end{array}$ & $\begin{array}{l}0.000 \mathrm{~m} \\
(0.0 \mathrm{pxl})\end{array}$ & $\begin{array}{l}0.001 \mathrm{~m} \\
(0.0 \mathrm{pxl})\end{array}$ & $\begin{array}{l}0.002 \mathrm{~m} \\
(0.0 \mathrm{pxl})\end{array}$ \\
\hline \multicolumn{7}{|c|}{$\varepsilon=15^{\circ}$} \\
\hline \multirow{2}{*}{$\Delta x$} & $R=10 \mathrm{~m}$ & $\begin{array}{l}-0.093 \mathrm{~m} \\
(-71 \mathrm{pxl})\end{array}$ & $\begin{array}{l}0.000 \mathrm{~m} \\
(0.0 \mathrm{pxl})\end{array}$ & $\begin{array}{l}0.005 \mathrm{~m} \\
(0.0 \mathrm{pxl})\end{array}$ & $\begin{array}{c}0.007 \mathrm{~m} \\
(0.0 \mathrm{pxl})\end{array}$ & $\begin{array}{l}0.000 \mathrm{~m} \\
(0.0 \mathrm{pxl})\end{array}$ \\
\hline & $R=20 \mathrm{~m}$ & $\begin{array}{l}-0.196 \mathrm{~m} \\
(-147 \mathrm{pxl})\end{array}$ & $\begin{array}{l}-0.010 \mathrm{~m} \\
(-1.0 \mathrm{pxl})\end{array}$ & $\begin{array}{l}0.000 \mathrm{~m} \\
(0.0 \mathrm{pxl})\end{array}$ & $\begin{array}{l}0.003 \mathrm{~m} \\
(0.0 \mathrm{pxl})\end{array}$ & $\begin{array}{l}0.005 \mathrm{~m} \\
(0.0 \mathrm{pxl})\end{array}$ \\
\hline \multicolumn{7}{|c|}{$\varepsilon=35^{\circ}$} \\
\hline \multirow{2}{*}{$\Delta x$} & $R=10 \mathrm{~m}$ & $\begin{array}{l}-0.206 \mathrm{~m} \\
(-155 \mathrm{pxl})\end{array}$ & $\begin{array}{l}0.000 \mathrm{~m} \\
(0.0 \mathrm{pxl})\end{array}$ & $\begin{array}{l}0.011 \mathrm{~m} \\
(0.5 \mathrm{pxl})\end{array}$ & $\begin{array}{l}0.015 \mathrm{~m} \\
(0.0 \mathrm{pxl})\end{array}$ & $\begin{array}{l}0.017 \mathrm{~m} \\
(0.0 \mathrm{pxl})\end{array}$ \\
\hline & $R=20 \mathrm{~m}$ & $\begin{array}{l}-0.436 \mathrm{~m} \\
(-327 \mathrm{pxl})\end{array}$ & $\begin{array}{l}-0.023 \mathrm{~m} \\
(-2.0 \mathrm{pxl})\end{array}$ & $\begin{array}{l}0.000 \mathrm{~m} \\
(0.0 \mathrm{pxl})\end{array}$ & $\begin{array}{l}0.008 \mathrm{~m} \\
(0.0 \mathrm{pxl})\end{array}$ & $\begin{array}{l}0.011 \mathrm{~m} \\
(0.0 \mathrm{pxl})\end{array}$ \\
\hline
\end{tabular}

The parallax error reveals itself as the stitching error $\left(\Delta x_{s}\right)$, which may be observed on the image as the displacement of pixels in the position of stitching two adjacent images created by the single pinhole cameras.

The stitching error is [15]:

$$
\Delta x_{s}=\left|\frac{1}{D}-\frac{1}{R}\right| \cdot C_{L D}[\mathrm{pxl}]
$$

where $C_{L D}$ is the constant value calculated from the equation that includes the distance between the adjacent sensors of the single pinhole cameras, focal length, and number of pixels on a sensor.

The parallax error is a characteristic feature of any part of the panorama, whereas stitching errors appear where overlapping images merge. The greatest parallax errors are obtained where $R$ and $D$ are small. 
In the object space, the parallax error is expressed as the location error $\left(\Delta X_{\text {lok }}\right)$ (Fig. 2) [10]:

$$
\begin{aligned}
& \Delta X_{\mathrm{lok}}=\frac{(D-R) \cdot t \cdot \operatorname{tg} \varepsilon}{R} \\
& \Delta Y_{\mathrm{lok}}=\frac{(D-R) \cdot t \cdot \operatorname{tg} \xi}{R}
\end{aligned}
$$

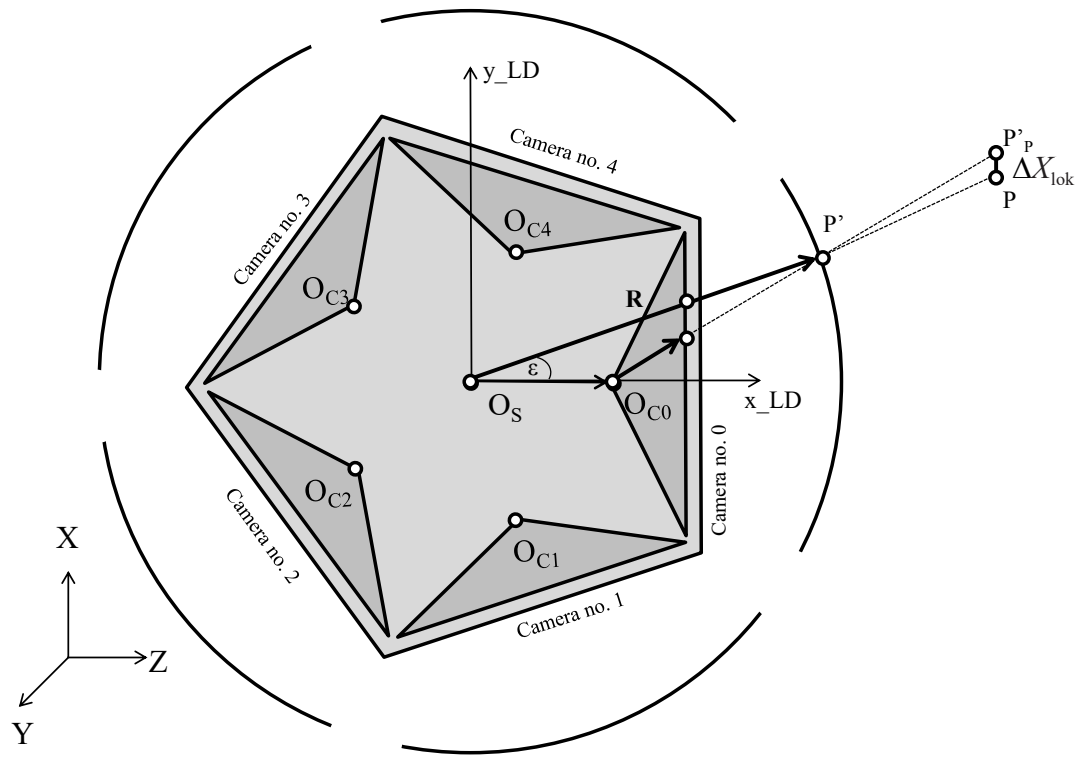

Fig. 2. Location error in direction of $X$ axis $\left(\Delta X_{\text {lok }}\right)$ is caused by selection of spherical model on immersive panorama

Displacement of the projection centers of the single pinhole cameras is also responsible for the so-called epipolar error $(\Delta E)$, which occurs when the coplanarity requirements cannot be met by the vectors of the homologous rays. These vectors go from the origin of the coordinate system of the immersive cameras to image points on the camera spheres. The epipolar error $(\Delta E)$ is expressed by Formula [10]:

$$
\Delta E=\mathbf{B} \cdot\left(\mathbf{N}_{1} \times \mathbf{N}_{2}\right)=B_{y}\left(T_{x_{2}}^{\prime}-T_{x_{1}}\right)-B_{x}\left(T_{y_{2}}^{\prime}-T_{y_{1}}\right)
$$

where:

B, $\mathbf{N}_{1}, \mathbf{N}_{2}$ - base vector and vectors of homologous rays in coplanarity formula for two immersive panoramas,

$B_{x^{\prime}} B_{y}$ - components of base vector in coordinate system of left panorama,

$T_{x^{\prime}} T_{y}$ - displacement vectors of individual cameras in coordinate system of two immersive cameras. 
The epipolar error can be minimized by the proper orientation of the zero camera axis during direct intersection (it is recommended to point the axis counter towards the direction of the immersive camera movement). The above-mentioned errors affect the quality of the photogrammetric measurements, and knowing how they depend on the parameters described in Equations (1)-(6) enables us to determine the accuracy of the planned measurements.

\section{Examination of Impact of Immersive Imaging Parameters on Photogrammetric Measurement Accuracy}

\subsection{Theoretical Analysis}

The application of the spherical model to the photogrammetric measurements based on images from the immersive camera burdens the measurement results with systematic errors. This paper investigates the values of the errors obtained from the direct intersection that relies on measurements in immersive images. A few standard variants of the intersection were considered (Fig. 3), differing mainly in intersecting horizontal angles $\left(\vartheta^{\prime}\right.$ and $\left.\vartheta^{\prime \prime}\right)$ and zenithal angles $\left(\varphi^{\prime}\right.$ and $\left.\varphi^{\prime \prime}\right)$; the configuration of the intersections was adjusted to standard configurations of camera location. It was assumed that the camera moves along a trajectory and that its location does not change within the variants. The most typical configuration was the one in which Camera 0 (Fig. 3) has its axis pointing against the direction of the immersive camera movement.

Figure 3 presents three representative locations of intersected points for the individual cameras that are the potential source of the points in the panorama. In video sequences, such a configuration occurs frequently. The location of point $\mathrm{P}_{0}$ is not affected by the eccentricity error of the projection center, since the image points are located on the axes of the single pinhole cameras (Cameras 3 and 4; Equations (1) and (2), $\varepsilon_{1}=\varepsilon_{2}=0^{\circ}$ ). Point $\mathrm{P}_{1}$ features the maximum impact of the parallax errors $\left(\varepsilon_{1}=\varepsilon_{2}=35^{\circ}\right.$; due to the configuration of the intersection, it was taken that $\xi_{1}=\xi_{2}=25^{\circ}$ ) because it is located on the edge of the field of view of the single pinhole cameras. What is more, the parallax errors have opposite signs here. The location of point $\mathrm{P}_{2}$ on immersive panoramas has impact of the parallax error as a typical case. The simulation of the error impact was run by changing the parallax errors calculated for a few variants $(D, R, \varepsilon$ and $\xi)$ for the intersection angle errors ( $d \vartheta$ and $\mathrm{d} \varphi$ - indicate the corrections for the horizontal and zenithal angles that were calculated as the angular equivalents of the parallax errors).

Table 2 presents exemplary variants of the maximum systematic errors of intersecting point coordinates $\Delta X^{\prime}, \Delta Y^{\prime}$, and $\Delta Z^{\prime}$ (in the configuration for point $\mathrm{P}_{1}$ ). These variants adopted the standard (for the Ladybug ${ }^{\circledR} 3$ camera) angles of the field of view - two values of $R(10 \mathrm{~m}$ and $20 \mathrm{~m})$ for the points located inside and outside 
the sphere. For the sake of comparison, the values of the ground sampling distances (GSD) and the estimated random error of the position of the intersecting direction $\left(m_{x}\right)$ are presented in Table 2.

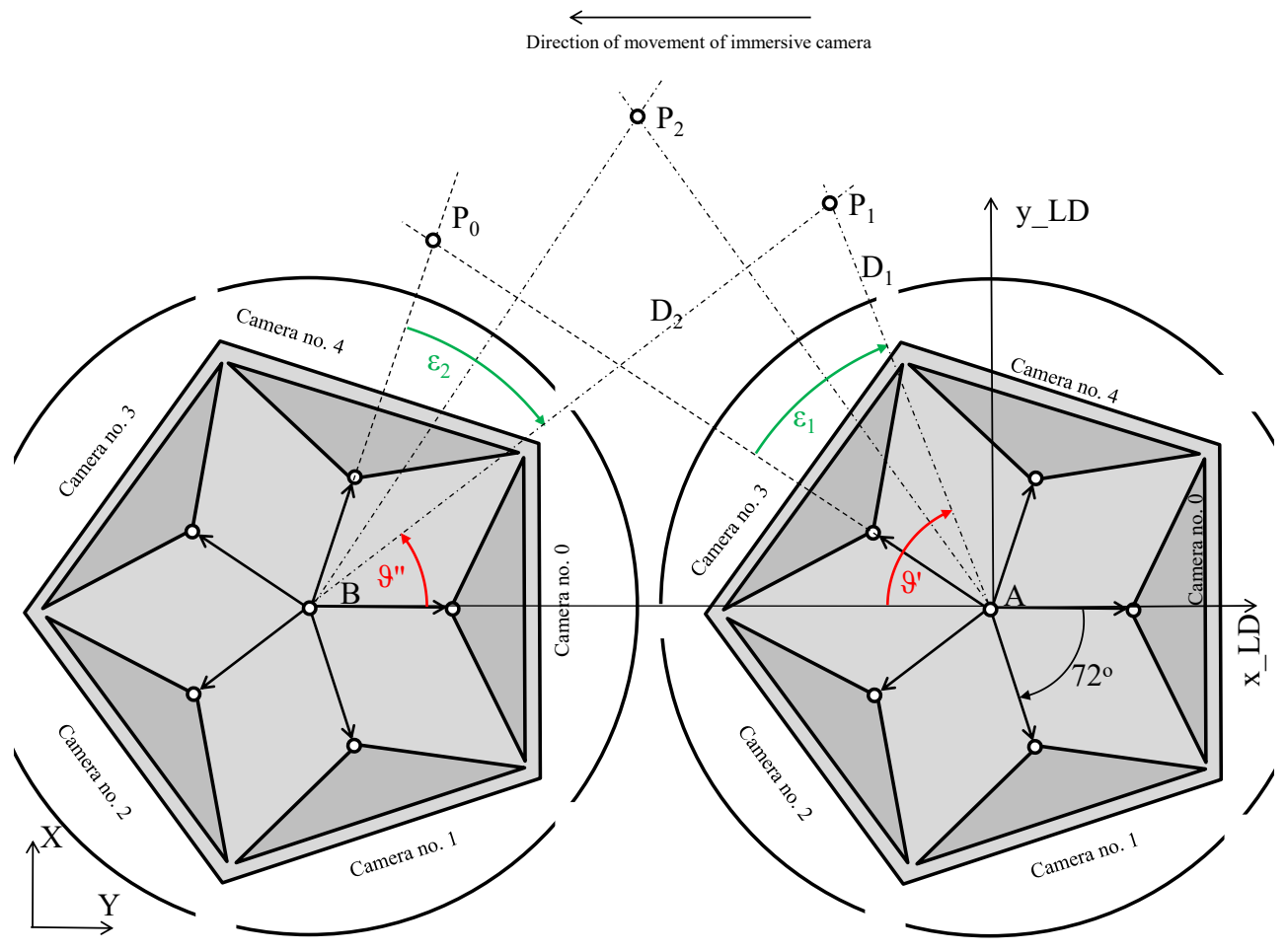

Fig. 3. Direct intersection from two immersive camera stations

Table 2. Maximum errors of spatial direct intersection for $\vartheta^{\prime}=71^{\circ}$ and $\vartheta^{\prime \prime}=37^{\circ}$ as well as $\varphi^{\prime}=65^{\circ}$ and $\varphi^{\prime \prime}=65^{\circ}$

\begin{tabular}{|c|c|c|c|c|c|c|}
\hline \multicolumn{3}{|c|}{$R=10 \mathrm{~m}$} & \multicolumn{4}{|c|}{$R=20 \mathrm{~m}$} \\
\hline \multicolumn{3}{|c|}{ outside the sphere } & \multicolumn{4}{|c|}{ outside the sphere } \\
\hline \multicolumn{2}{|c|}{$\begin{array}{l}D>10 \mathrm{~m} \\
D_{1}=20 \mathrm{~m} ; D_{2}=28.119 \mathrm{~m} \\
\mathrm{~d} \vartheta^{\prime}=-0^{\circ} .0288\left(\varepsilon_{1}=35^{\circ}\right) \\
\mathrm{d} \vartheta^{\prime \prime}=0^{\circ} .0264\left(\varepsilon_{2}=35^{\circ}\right) \\
\mathrm{d} \varphi^{\prime}=0^{\circ} .0212\left(\xi=25^{\circ}\right) \\
\mathrm{d} \varphi^{\prime}=0^{\circ} .0194\left(\xi=25^{\circ}\right)\end{array}$} & $\begin{array}{l}B=28.284 \mathrm{~m} \\
\mathrm{GSD}_{1}=0.027 \mathrm{~m} \\
\mathrm{GSD}_{2}=0.037 \mathrm{~m} \\
m_{x}=0.022 \mathrm{~m}\end{array}$ & \multicolumn{2}{|c|}{$\begin{array}{l}D>20 \mathrm{~m} \\
D_{1}=40 \mathrm{~m} ; D_{2}=62.478 \mathrm{~m} \\
\mathrm{~d} \vartheta^{\prime}=-0^{\circ} .0144\left(\varepsilon_{1}=35^{\circ}\right) \\
\mathrm{d} \vartheta^{\prime \prime}=0^{\circ} .0125\left(\varepsilon_{2}=35^{\circ}\right) \\
\mathrm{d} \varphi^{\prime}=0^{\circ} .0106\left(\xi=25^{\circ}\right) \\
\mathrm{d} \varphi^{\prime \prime}=0^{\circ} .0092\left(\xi=25^{\circ}\right)\end{array}$} & \multicolumn{2}{|c|}{$\begin{array}{l}B=56.568 \mathrm{~m} \\
\mathrm{GSD}_{1}=0.053 \mathrm{~m} \\
\mathrm{GSD}_{2}=0.083 \mathrm{~m} \\
m_{x}=0.049 \mathrm{~m}\end{array}$} \\
\hline$\Delta X^{\prime}$ & $\Delta Y^{\prime}$ & $\Delta Z^{\prime}$ & $\Delta X^{\prime}$ & $\Delta Y^{\prime}$ & & $\Delta Z^{\prime}$ \\
\hline $0.008 \mathrm{~m}$ & $-0.012 \mathrm{n}$ & $-0.012 \mathrm{~m}$ & $0.007 \mathrm{~m}$ & -0.012 & & $-0.012 \mathrm{~m}$ \\
\hline
\end{tabular}




\begin{tabular}{|c|c|c|c|c|c|c|}
\hline \multicolumn{4}{|c|}{ inside the sphere } & \multicolumn{3}{|c|}{ inside the sphere } \\
\hline \multicolumn{2}{|c|}{$\begin{array}{l}5 \leq D<10 \mathrm{~m} \\
D_{1}=5 \mathrm{~m} ; D_{2}=7.030 \mathrm{~m} \\
\mathrm{~d} \vartheta^{\prime}=0^{\circ} .2300\left(\varepsilon_{1}=35^{\circ}\right) \\
\mathrm{d} \vartheta^{\prime \prime}=-0^{\circ} .0691\left(\varepsilon_{2}=35^{\circ}\right) \\
\mathrm{d} \varphi^{\prime}=-0^{\circ} .2300\left(\xi=25^{\circ}\right) \\
\mathrm{d} \varphi^{\prime \prime}=-0^{\circ} .0509\left(\xi=25^{\circ}\right)\end{array}$} & \multicolumn{2}{|c|}{$\begin{array}{l}B=7.071 \mathrm{~m} \\
\mathrm{GSD}_{1}=0.007 \mathrm{~m} \\
\mathrm{GSD}_{2}=0.009 \mathrm{~m} \\
m_{x}=0.005 \mathrm{~m}\end{array}$} & \multicolumn{2}{|c|}{$\begin{array}{l}12 \leq D<20 \mathrm{~m} \\
D_{1}=12 \mathrm{~m} ; D_{2}=16.871 \mathrm{~m} \\
\mathrm{~d} \vartheta^{\prime}=0^{\circ} .0639\left(\varepsilon_{1}=35^{\circ}\right) \\
\mathrm{d} \vartheta^{\prime \prime}=-0^{\circ} .0126\left(\varepsilon_{2}=35^{\circ}\right) \\
\mathrm{d} \varphi^{\prime}=-0^{\circ} .0639\left(\xi=25^{\circ}\right) \\
\mathrm{d} \varphi^{\prime \prime}=-0^{\circ} .0093\left(\xi=25^{\circ}\right)\end{array}$} & $\begin{array}{l}B=16.970 \mathrm{~m} \\
\mathrm{GSD}_{1}=0.016 \mathrm{~m} \\
\mathrm{GSD}_{2}=0.022 \mathrm{~m} \\
m_{x}=0.013 \mathrm{~m}\end{array}$ \\
\hline$\Delta X^{\prime}$ & $\Delta Y^{\prime}$ & & $\Delta Z^{\prime}$ & $\Delta X^{\prime}$ & $\Delta Y^{\prime}$ & $\Delta Z^{\prime}$ \\
\hline $0.003 \mathrm{~m}$ & 0.020 & & $0.018 \mathrm{~m}$ & $0.004 \mathrm{~m}$ & $0.012 \mathrm{n}$ & $0.011 \mathrm{~m}$ \\
\hline
\end{tabular}

The data analysis indicates that, although the coordinate errors are comparable for all of the variants as compared to the ground sampling distances for the small $R$ and $D$ inside the sphere, the intersection errors are significant, especially in the vertical plane parallel to the intersection base.

\subsection{Measurement Tests}

The accuracy of the photogrammetric measurements from the immersive panoramas depends mainly on the accepted sphere radius $(R)$ and its relation with the distance to object points $D$ and the location of the points on the individual images (described my means of angles $\varepsilon$ and $\xi$ ). The influence of other factors such as the base length or orientation of the individual cameras used to take two adjacent panoramas will be discussed in further publications related to immersive panoramas.

In the immersive video, the elements that can be easily adjusted are the sphere radius (selected after registration) and the angle between the projecting ray and axes of the single pinhole cameras (due to the mask application). The above-mentioned parameters influence the parallax errors, which are responsible for the correct measurements. The photogrammetric test measurements were carried out with a Ladybug 3 camera, the panoramas were stitched from images using the camera's dedicated software, and the panorama network was aligned in the Photoscan software by Agisoft.

\subsection{Examination of Sphere Radius Change Impact}

The aim of the research was to investigate how changing the immersive panorama sphere radius $(R)$ influences the photogrammetric measurements depending on the distances to the surveyed points. The survey was carried out on a test field set up in the Main Hall of the A-0 building belonging to AGH University of Science and Technology in Krakow. Inside the hall (whose size is $24 \times 12 \times 10 \mathrm{~m}$ ), an immersive video was recorded on stations located on the room symmetry lines. Two immersive panoramas were selected from the recordings. For these panoramas, the sphere radii were set (at $4 \mathrm{~m}, 5 \mathrm{~m}, 7 \mathrm{~m}$, and $10 \mathrm{~m}$ ). The photogrammetric control in the form of 
ground control points was measured using the total station, and the error of determining the ground control point position was $3 \mathrm{~mm}$.

The accuracy indicator in this survey is the root-mean errors on the ground control points after the network adjustment. Three ranges of distances from the immersive camera were selected.

In these ranges, the ground control points were located; the ranges were as follows:

- A: 5.68-6.68 m (minimum range; 8 ground control points);

- B: 7.64-8.64 m (medium range; 8 ground control points);

- C: $10.85-11.85 \mathrm{~m}$ (maximum range; 6 ground control points);

Table 3 presents the mean errors on the ground control points for the X, Y, and $\mathrm{Z}$ axes. Figure 4 depicts the mean errors on the ground control points for the chosen sphere radii. In Range $A$, the ground sampling distance averages $8 \mathrm{~mm}$, in Range $\mathrm{B}-10 \mathrm{~mm}$, and in Range C $-15 \mathrm{~mm}$ (these values are drawn on the chart [Fig. 4]). The analysis of the results in Table 3 and the chart created on this basis reveals that the best results were obtained for sphere radius $R=7 \mathrm{~m}$ for all distance ranges (and additionally for $R=10 \mathrm{~m}$ for Range C). For $R=4 \mathrm{~m}$ and $R=5 \mathrm{~m}$ for all ranges, the mean errors were equal to or greater than $2 \mathrm{~cm}(4-5 \times$ greater than GSD).

Table 3. Mean errors on ground control points depending on sphere radius and adopted range

\begin{tabular}{|c|c|c||}
\hline \multirow{2}{*}{$R[\mathrm{~m}]$} & Range & $\begin{array}{c}\mathrm{RMSE}_{\mathrm{XYZ}} \\
{[\mathrm{mm}]}\end{array}$ \\
\hline \hline \multirow{4}{*}{4} & $\mathrm{~A}$ & 20 \\
\cline { 2 - 3 } & $\mathrm{B}$ & 26 \\
\cline { 2 - 3 } & $\mathrm{C}$ & 23 \\
\hline \multirow{4}{*}{5} & $\mathrm{~A}$ & 20 \\
\cline { 2 - 3 } & $\mathrm{B}$ & 25 \\
\cline { 2 - 3 } & $\mathrm{C}$ & 21 \\
\hline \multirow{3}{*}{7} & $\mathrm{~A}$ & 14 \\
\cline { 2 - 3 } & $\mathrm{B}$ & 13 \\
\cline { 2 - 3 } & $\mathrm{C}$ & 15 \\
\hline \multirow{3}{*}{10} & $\mathrm{~A}$ & 18 \\
\cline { 2 - 3 } & $\mathrm{B}$ & 16 \\
\cline { 2 - 3 } & $\mathrm{C}$ & 15 \\
\hline
\end{tabular}

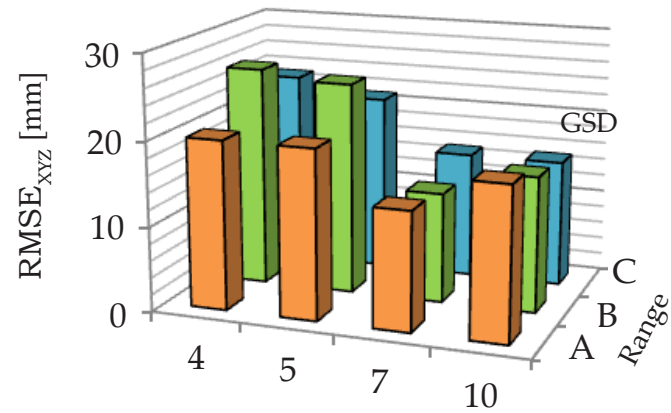

口.A $\mathrm{B} B \mathrm{C} \quad \mathrm{R}[\mathrm{m}]$

Fig. 4. Chart showing relationships between ranges and $\mathrm{RMSE}_{\mathrm{XYZ}}$

A comparison of the results with the ground sampling distance (Fig. 4) allows for the conclusion that the selection of sphere radius $R=7 \mathrm{~m}$ decreases the impact of immersion to the ground sampling distance for Range $C$ (and only slightly above the 
ground sampling distance for Ranges $\mathrm{A}$ and $\mathrm{B}$ ). The selection of $R=10 \mathrm{~m}$ minimizes the errors for Range C.

In general, a sphere radius whose length is similar to the average distance to the points is regarded as the most convenient one. It is recommended to use an $R$ that is shorter than the range in which the measured points are located (or slightly shorter than an average distance to the camera) so that the points can be on the sphere or outside the sphere.

\subsubsection{Examination of Impact of Masking Circle Radius Changes}

The masking circle radius is connected to angles $\varepsilon$ and $\xi$. The field of view of each individual camera can be limited by creating masks on the image with a transparent circle with a radius of $r_{a^{\prime}}$ which is concentric in relation to the principal point of each individual camera (the examination does not include the camera pointing upwards). To simplify the analysis, it was agreed that $\varepsilon=\xi$.

On the test field located on the AGH University campus in Krakow, 71 immersive panoramas were created whose sphere radii were $R=20 \mathrm{~m}$. The immersive camera moved along a trajectory parallel to the campus building facades, approximately $20 \mathrm{~m}$ from one facade $\left(\mathrm{GSD}_{1}=0.026 \mathrm{~m}\right)$ and about $40 \mathrm{~m}$ from the opposite facade $\left(\mathrm{GSD}_{2}=0.052 \mathrm{~m}\right)$. The average base length for the panoramas was about $0.5 \mathrm{~m}$. The panoramas were recorded with a camera mounted on a car roof, which was a component of the mobile mapping system designed by the author. Figure 5 presents the selected radii of the masking circle, which were later linked with the immersive images. This study uses mean errors on the ground control points and on the control points, which are not involved in the network adjustment as accuracy indicators.
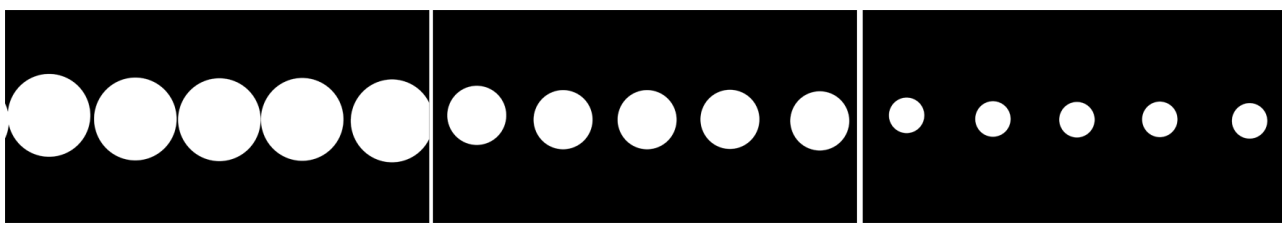

Fig. 5. Masks with set radius of masking circle: $35^{\circ} ; 25^{\circ}$; and $15^{\circ}$

As the masking circle radius decreases, the average error values drop as well (Tab. 4). So does the number of visible ground control points and check points. Figure 6 presents the root-mean errors on the ground control points for three radii of the masking circle (two ground sampling distances on two facades are also indicated).

Figure 6 indicates that, by reducing the masking circle radius from $35^{\circ}$ to $25^{\circ}$, the number of mean errors on the ground control points decrease (they do not exceed ground sampling distances $\mathrm{GSD}_{1}$ and $\mathrm{GSD}_{2}$ ). The number of visible ground control points also dropped by 33\% (from 18 to 12). 
Table 4. Root-mean errors after applying three radii of masking circle

\begin{tabular}{|c|c|c|c|c|c|c|c|}
\hline \multirow{2}{*}{$\begin{array}{l}\varepsilon / \xi \\
{\left[{ }^{\circ}\right]} \\
\end{array}$} & \multirow{2}{*}{$\begin{array}{c}r_{a} \\
{[\mathrm{pxl}]}\end{array}$} & \multirow{2}{*}{\multicolumn{2}{|c|}{$\begin{array}{c}\text { Number of ground } \\
\text { control points/ } \\
\text { control points }\end{array}$}} & \multicolumn{4}{|c|}{ Root-mean error $[\mathrm{mm}]$} \\
\hline & & & & $\mathrm{RMSE}_{\mathrm{x}}$ & $\mathrm{RMSE}_{\mathrm{Y}}$ & $\mathrm{RMSE}_{\mathrm{z}}$ & $\mathrm{RMSE}_{\mathrm{XYZ}}$ \\
\hline \multirow{2}{*}{35} & \multirow{2}{*}{525} & GCP & 18 & 43 & 28 & 24 & 57 \\
\hline & & $\mathrm{CP}$ & 18 & 43 & 27 & 26 & 57 \\
\hline \multirow{2}{*}{25} & \multirow{2}{*}{375} & GCP & 12 & 26 & 18 & 8 & 33 \\
\hline & & $\mathrm{CP}$ & 13 & 31 & 20 & 14 & 39 \\
\hline \multirow{2}{*}{15} & \multirow{2}{*}{225} & GCP & 8 & 18 & 11 & 8 & 23 \\
\hline & & $\mathrm{CP}$ & 6 & 22 & 17 & 12 & 30 \\
\hline
\end{tabular}

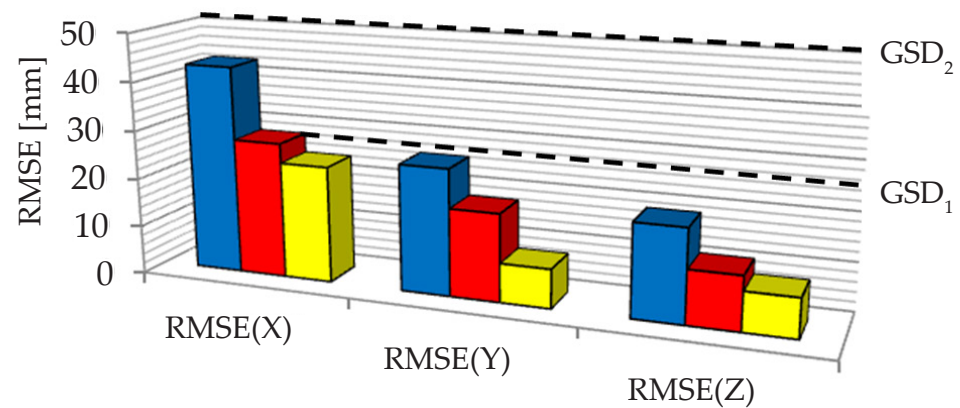

$\square \varepsilon=35^{\circ}$

$\square \varepsilon=25^{\circ}$

$\square \varepsilon=15^{\circ}$

Fig. 6. Root-mean errors on ground control points depending on masking circle radii

\section{Summary and Conclusions}

The imaging errors in the immersive image result mainly from the parallax errors. The parallax errors depend mainly on the accepted sphere radius $(R)$, distance to the object $(D)$ (in particular, the $D$ - $R$ difference), and distance from the main point of the individual camera $\left(r_{a}\right)$. These are the parameters that can be adjusted by the user. Other parameters (e.g., the displacement of individual cameras [ $t$ ] from the "virtual" projection center of the immersive camera) can be changed only at the camera design stage.

To sum up, the sphere radius $(R)$ of the immersive panorama used for the photogrammetric measurements should be smaller than the average range of the measured points. The points should be located on the sphere or outside the sphere. The mean errors on the ground control points can be decreased by selecting a smaller radius of the masking circle. The immersive image errors should be compared to the ground sampling distance. 


\section{Acknowledgements}

The authors wish to express their gratitude to Mr. Cezary Śliwkowski for his help in the realization of the project.

\section{References}

[1] Kwiatek K., Tokarczyk R.: Immersive photogrammetry in 3D modelling. Geomatics and Environmental Engineering, vol. 9, no. 2, 2015, pp. 51-62.

[2] Barazzetti L., Fangi G., Remondino F., Scaioni M.: Automation in multi-image spherical photogrammetry for 3D architectural reconstructions. [in:] VAST 2010: The 11th International Symposium on Virtual Reality, Archaeology and Intelligent Cultural Heritage; the 8th EUROGRAPHICS Workshop on Graphics and Cultural Heritage ; Paris, France, September 21-24, 2010, The Eurographics Association, 2010, pp. 75-81.

[3] d'Annibale E., Fangi G.: Interactive modeling by projection of oriented spherical panorama. International Archives of the Photogrammetry, Remote Sensing and Spatial Information Sciences, vol. XXXVIII-5/W1, 2009, pp. 1682-1777.

[4] d'Annibale E., Malinverni E.S.: From panoramic photos to a low-cost photogrammetric workflow for cultural heritage 3D documentation. International Archives of the Photogrammetry, Remote Sensing and Spatial Information Sciences, vol. XL-5/W2, 2013, pp. 213-218.

[5] Fangi G.: The Multi-image spherical Panoramas as a tool for Architectural Survey. CIPA Heritage Documentation, vol. 21, 2011, pp. 311-316.

[6] Fangi G, Nardinocchi C.: Photogrammetric processing of spherical panoramas. The Photogrammetric Record, vol. 28, no. 143, 2013, pp. 293-311.

[7] Wahbeh W.: Architectural Digital Photogrammetry: Panoramic Image-Based Interactive Modelling. University Sapienza of Rome, Italy 2011 [unpublished Ph.D. thesis].

[8] Wahbeh W., Nardinocchi C.: Toward the Interactive 3D Modelling Applied to Ponte Rotto in Rome. Nexus Network Journal, vol. 17, no. 1, 2015, pp. 55-71.

[9] Fujiki J., Akihiko T., Shotaro A.: Epipolar geometry via rectification of spherical images. [in:] Gagalowicz A., Philips W. (eds.), Computer Vision/Computer Graphics Collaboration Techniques: Third International Conference, MIRAGE 2007, Rocquencourt, France, March 28-30, 2007. Proceedings, Lecture Notes in Computer Science, vol. 4418, Springer, Berlin - Heidelberg 2007, pp. 461-471.

[10] Ji S., Shi Y., Shi Z., Bao A., Li J., Yuan X., Duan Y., Shibasaki R.: Comparison of two panoramic sensor models for precise $3 d$ measurements. Photogrammetric Engineering \& Remote Sensing, vol. 80, no. 3, 2014, pp. 229-238.

[11] Parian J.A.: Sensor modeling, calibration and point positioning with terrestrial panoramic cameras. Eidgenössische Technische Hochschule, Zürich 2007 [dissertation]. 
[12] Schmeing B., Läbe T., Förstner W.: Trajectory reconstruction using long sequences of digital images from an omnidirectional camera. [in:] Vorträge: 31. Wissenschaftlich-Technische Jahrestagung der DGPF: 13. - 15. April 2011 in Mainz, Publikationen der Deutschen Gesellschaft für Photogrammetrie, Fernerkundung und Geoinformation e.V.: Geodaten - eine Ressource des 21. Jahrhunderts, Band 20, DGPF, Münster 2011, pp. 443-452.

[13] Shi Y., Ji S., Shi Z., Duan Y., Shibasaki R.: GPS-supported visual SLAM with a rigorous sensor model for a panoramic camera in outdoor environments. Sensors, vol. 13, no. 1, 2012, pp. 119-136.

[14] Point Grey Research Inc.: Geometric Vision using Ladybug Cameras. 2014, [on-line:] http://www.ptgrey.com/support/downloads/10400 [access: 12.03.2017].

[15] Point Grey Research Inc.: Overview of the Ladybug Image Stitching Process. Technical Application Note TAN2008010. 2014, [on-line:] https://www. ptgrey.com/support/downloads/10378 [access: 15.03.2017].

\section{Pomiary fotogrametryczne 3D na podstawie panoram imersyjnych}

Streszczenie: Artykuł przedstawia koncepcję pomiarów fotogrametrycznych z wideo imersyjnego, czyli wideo zarejestrowanego w ruchu przez kamerę imersyjną. Taka kamera rejestruje obrazy w zakresie $360^{\circ}$ dzięki zastosowaniu kilku kamer składowych, których środki rzutów są oddalone od wspólnego „wirtualnego” środka rzutów.

Celem artykułu jest analiza dokładności pomiarów wykonywanych na podstawie panoram imersyjnych. W artykule przedstawiono geometrię modelu imersyjnego, a także wykorzystanie obrazowania imersyjnego w modelu sferycznym, który jest stosowany w programie typu SfM (np. Photoscan). Zbadany został wpływ parametrów obrazowania imersyjnego na dokładność pomiaru fotogrametrycznego. Dokładność pomiarów fotogrametrycznych na podstawie panoram imersyjnych zależy przede wszystkim od przyjętego promienia sfery $R$ i jego relacji z odległością do punktów obiektu $D$ oraz od położenia punktów na zdjęciach składowych, wyrażanego przez kąty $\varepsilon$ i $\xi$. W artykule przeanalizowano wpływ zmian promienia sfery $R$ oraz wpływ zmian promienia koła maskowania na dokładność pomiarów na podstawie panoram imersyjnych.

$Z$ badań wynika, że promień sfery $R$ panoramy imersyjnej wykorzystywanej do pomiarów fotogrametrycznych powinien być dobierany w taki sposób, aby był mniejszy niż średni zakres punktów pomiarowych, natomiast redukcja promienia koła maskowania zmniejsza błędy średnie na fotopunktach.

\section{Słowa}

kluczowe: panorama, imersyjne wideo, wideo $360^{\circ}$, kamera Ladybug, fotogrametria sferyczna 